Check for updates

Cite this: RSC Adv., 2017, 7, 52357

Received 4th July 2017

Accepted 31st October 2017

DOI: 10.1039/c7ra07381j

rsc.li/rsc-advances

\section{Effect of xylose on the structural and physicochemical properties of peanut isolated protein based films}

\author{
Li Liu, (D) $\dagger^{\mathrm{ab}}$ Wei-Jing Lin, $\dagger^{\mathrm{a}}$ Hong-Zhi Liu, ${ }^{a}$ Ai-Min Shi, ${ }^{a}$ Hui Hu, ${ }^{a}$ Mehmet Nail Nasir, ${ }^{b}$ \\ Magali Deleu*b and Qiang Wang*a
}

Films based on xylose and peanut protein isolate (PPI) were prepared by solution casting. The effects of xylose content $(1 \%, 2 \%, 5 \%, 10 \%, 20 \% \mathrm{PPI}, \mathrm{w} / \mathrm{w})$ on the structure and mechanical properties of PPIxylose (PPI-X) film were systematically investigated. The xylose-modified PPI was firstly prepared by crosslinking and modifying of peanut isolated protein with xylose. The degree of glycosylation and surface hydrophobicity significantly increased from $5.6 \%$ to $10.9 \%$ and from 130.6 to 370.0 , respectively, with the increase of the xylose content. Maillard reactions occurring between PPI and xylose were confirmed by Fourier transform infrared spectroscopy. Then the xylose-modified PPI was developed into films. PPI-X films showed markedly increased tensile strength (increased by $77 \%$ ) and elongation (increased by $67 \%$ ) and decreased solubility (from $96.6 \%$ to $43.4 \%$ ) compared to PPI films, suggesting that the incorporation of xylose could markedly enhance the mechanical properties and the water resistance of films. This property improvement was correlated to the increased protein surface hydrophobicity and sulfhydryl group content with the addition of xylose. No significant differences were detected among $L^{*}, a^{*}, b^{*}$ colour values of all films $(P>0.05)$. The scanning electron microscope images of the PPI-X film showed that the addition of xylose up to $10 \%$ produced a more homogeneous and denser structure. Finally, the improvement mechanism of the PPI-X film was proposed.

\section{Introduction}

Biodegradable films have gained increasing research interest due to their potential use in food packaging. They are obtained from renewable and natural biopolymers such as proteins, polysaccharides and their combinations. Among them, proteinbased materials such as soybean, wheat gluten, and peanut protein films are the most attractive candidates to replace nonbiodegradable plastics because they are environmentally friendly, and have similar physical and mechanical properties compared to synthetic films. ${ }^{1-4}$

Peanut meal is a byproduct generated during oil extraction and is mainly used as animal feed and fertilizer in China. ${ }^{36}$ Peanut protein isolate (PPI), extracted from peanut meal, has a low cost, presents good biodegradability and ability to

\footnotetext{
${ }^{a}$ Institute of Food Science and Technology, Chinese Academy of Agricultural Sciences, Key Laboratory of Agro-Products Processing, Ministry of Agriculture, P.O. Box 5109, Beijing 100193, China. E-mail: wangqiang06@caas.cn; liulio2@caas.cn; llwjing@ foxmail.com; lhz0416@126.com; sam_0912@163.com; littleh@vip.sina.com; Fax: +8610 62815837; Tel: +861062815837

${ }^{b}$ AgricultureisLife Plateform, Laboratoire de Biophysique Moléculaire aux Interfaces, Gembloux Agro-Bio Tech - University of Liege, Passage des Déportés 2, 5030 Gembloux, Belgium. E-mail: magali.deleu@ulg.ac.be; mn.nasir@ulg.ac.be

$\dagger$ Li Liu and Wei-Jing Lin contributed equally to this article.
}

polymerize, and could then be a good source to develop films for various applications. ${ }^{5}$

However, protein-based films have relatively low tensile strength, low elongation and water resistance compared to synthetic films, due to the hydrophilicity of plant proteins. ${ }^{5}$ The crosslinking or blending with polymers is one approach used to make the protein films suitable for practical use. Most proteinbased films use glycerol as a plasticizer to improve the elongation of the film. Modification of peanut proteins by glycosylation or cross-linking with saccharides is a potential way to improve the mechanical strength and the barrier properties of the films by reinforcing the intermolecular bonds. ${ }^{6-8}$

In literature, several recent papers deal with the improvement of the mechanical and barrier properties of protein-based films by glycosylation reactions. ${ }^{\mathbf{4 , 9 , 1 0}}$ Glycosylation with gum arabic $^{11}$ or glucomannan ${ }^{9}$ increases the tensile strength, decreases the water vapor permeability of protein films, but decreases the elongation ability. Generally, plasticizers having a smaller molecular weight show an easier incorporation into the protein matrix than plasticizers with a larger molecular weight. $^{\mathbf{1 2 , 1 3}}$ They also exhibit a more efficient plasticizing effect and lead to a stronger and tighter protein networking with stronger intermolecular covalent bonds. Lin et al., ${ }^{4,7}$ reported that crosslinking with xylose increases the strength and elongation of peanut protein films and also decreases quite 
remarkably their solubility in water. Therefore, xylose could be a good choice for the formation of protein-polysaccharides films. A previous study was focused on the optimization of $\mathrm{pH}$, temperature and time of reaction to obtain the xylose glycosylated protein (PPI-X) solutions. ${ }^{4}$ The effect of PPI-X dissolution temperature and glycerol concentration on mechanical properties and water solubility of glycosylated films were also investigated. ${ }^{7}$ However, only little information exists on the molecular structure and physicochemical properties of peanut protein films cross-linked with different xylose content.

In this context, one goal of this work was to provide an array of data to support comparative characterization of PPI film, at various levels of addition of xylose $(1 \%, 2 \%, 5 \%, 10 \%, 20 \%$, w/ $w)$. In this research, peanut protein isolate (PPI) was glycosylated with xylose, and the glycosylated PPI solution was converted into powder. The effect of xylose on the structure of xylose-modified PPI was analyzed in detail. In addition, the glycosylated PPI was used to form films. The effects of glycosylation on the tensile strength and elongation, solubility in water, color, sulfhydryl groups content and microstructure of PPI-X films were evaluated. Finally, the mechanism of PPI-X film formation was also proposed.

\section{Materials and methods}

\subsection{Materials and chemicals}

Peanut meal with a protein content of $47.81 \%$ was purchased from Gaotang Lanshan Co., Ltd. (Shandong Province, China). Xylose, $\mathrm{NaOH}$ and $\mathrm{NaBr}$ (Sinopharm Chemical Reagent Co., Ltd., Beijing, China) used in the experiments were analytical grade and used without further purification.

\subsection{Preparation of peanut protein isolated (PPI)}

Peanut protein isolate (PPI) was extracted from the peanut meal according to previous study with slight modifications. ${ }^{4}$ Briefly, peanut meal was dissolved in $(1: 10, \mathrm{w} / \mathrm{v})$ deionized water, the $\mathrm{pH}$ of dispersions was adjusted to 9.0. After stirring with $150 \mathrm{rpm}$ for $2 \mathrm{~h}$ at $25{ }^{\circ} \mathrm{C}$, the supernatant was obtained by centrifuging at $3500 \mathrm{~g}$ for $10 \mathrm{~min}$. The $\mathrm{pH}$ of the supernatant was adjusted to $\mathrm{pH} 4.5$. After centrifuging at $3500 \mathrm{~g}$ for $10 \mathrm{~min}$, the precipitate (peanut protein isolated) was recovered and freeze dried. The protein content was $90.93 \pm 1.36 \%$.

\subsection{Preparation of xylose-modified PPI powder}

PPI was modified with xylose by glycosylation, at five different ratios of xylose: $0.01 \mathrm{~g}, 0.02 \mathrm{~g}, 0.05 \mathrm{~g}, 0.10 \mathrm{~g}, 0.20 \mathrm{~g} \mathrm{~g}^{-1}$ PPI. The pH was adjusted to 9.0 using $1 \mathrm{~mol} \mathrm{~L}^{-1} \mathrm{NaOH}$ and the solutions were heated at $90{ }^{\circ} \mathrm{C}$ for $90 \mathrm{~min}$. The mixtures were then spraydried to obtain the PPI-X powder.

\subsection{Film preparation}

The film-forming solutions were prepared by dispersing PPI, or xylose-modified PPI in distilled water $(5 \%, \mathrm{w} / \mathrm{w})$. Glycerol was added at $25 \%$ of the total components. After degassing by filtrating through nylon filters, $15 \mathrm{~mL}$ of the film forming solutions were poured onto nonstick plates (15 cm diameter). Films were dried at $60{ }^{\circ} \mathrm{C}$ for $1 \mathrm{~h}$ and peeled entirely after cooling. The peeled films were conditioned at $58 \%$ relative humidity $(\mathrm{RH})$ for at least $48 \mathrm{~h}$ prior to analysis.

\subsection{Structural characterization of the xylose-modified PPI powder}

2.5.1. Determination of the degree of glycosylation. The degree of glycosylation (DG) of PPI-X power were determined by applying the method using OPA (o-phthalaldehyde) as described by Zhang et $a .^{14}$

2.5.2. Surface hydrophobicity. The surface hydrophobicity $\left(H_{0}\right)$ of PPI-X was determined according to the method of $\mathrm{He}$ et $a l .{ }^{15}$ using 1 -anilinonaphthalene- 8 -sulfonic acid (ANS) as the fluorescence probe. Protein solution $\left(1 \mathrm{mg} \mathrm{mL}^{-1}\right)$ was prepared in PBS (10 mM, pH 7.0). After incubation at $20{ }^{\circ} \mathrm{C}$ for $2 \mathrm{~h}$, the mixture was centrifuged at $10000 \mathrm{~g}$ for $20 \mathrm{~min}$. Protein concentration of the supernatant was determined with Folin phenol method. Fluorescence intensity was measured at $490 \mathrm{~nm}$ after excitation at $390 \mathrm{~nm}$. The initial slope of fluorescence intensity versus protein concentration plot was used as an index of $H_{0}$.

2.5.3. Fourier transform infrared spectroscopy (FTIR). FTIR of xylose, PPI and PPI-X were carried out on a FTIR spectrophotometer (Bruker, Madison, USA). The sample was ground with spectroscopic grade potassium bromide $(\mathrm{KBr})$ powder and then pressed into a $1 \mathrm{~mm}$ pellet for FTIR measurement in the frequency range of $4000-400 \mathrm{~cm}^{-1}$.

\subsection{Characterization of the mechanical, structural and physical properties of the films}

2.6.1. Mechanical properties. Tensile strength (TS) and elongation at break $(E)$ of all films were determined using a TATX2i texture analyzer (Stable Micro System Ltd., Godalming, UK) according to ASTM standard method D882-01.

\subsubsection{Physical properties}

2.6.2.1. Solubility in water. The total soluble matter (TSM) of the films was calculated by employing the method described by Lin et $a .^{7}$ The initial dry matter of the preconditioned film pieces $(2 \times 2 \mathrm{~cm})$ was determined by drying in an air-circulating oven at $105{ }^{\circ} \mathrm{C}$ for $24 \mathrm{~h}\left(W_{\mathrm{i}}\right)$. The insoluble matter was separated carefully and dried at $105{ }^{\circ} \mathrm{C}$ for $24 \mathrm{~h}$ for determination of the final dry weight $\left(W_{\mathrm{f}}\right)$. All tests were carried out in triplicate, and the total soluble matter (\%) in the film was calculated by using the following equation: TSM $=\left(W_{\mathrm{i}}-W_{\mathrm{f}}\right) / W_{\mathrm{i}} \times 100 \%$.

2.6.2.2. Color. The color of the films was determined with a colorimeter (CR-400, Konica Minolta co., LTD, Japan). $L^{*}, a^{*}$, and $b^{*}$ color values were measured in triplicate.

\subsubsection{Characterization of structural properties}

2.6.3.1. Sulfhydryl groups content. The contents of sulfhydryl groups $(\mathrm{SH})$ were determined according to the methods of Beveridge et $a .^{16}$ with slight modifications. Briefly, protein samples $(60 \mathrm{mg})$ were dispersed in Ttris-glycine buffer $(0.086 \mathrm{M}$ Tris, $0.09 \mathrm{M}$ glycine, $4 \mathrm{mM}$ EDTA, $\mathrm{pH}$ 8.0) in a blender containing $8 \mathrm{M}$ urea, and mixed by shaking for $24 \mathrm{~h}$ at $25{ }^{\circ} \mathrm{C}$. The mixture was then centrifuged at $10000 \mathrm{~g}$ for $10 \mathrm{~min}$ to obtain the supernatant. Ellman's reagent $\left(4 \mathrm{mg} \mathrm{mL}^{-1}\right)$ was added to the 
supernatant. The absorbance of the mixture was determined at $412 \mathrm{~nm}$. A solution without protein was used as blank control.

2.6.3.2. Microstructure. Film microstructure was observed using Hitachi S570 scanning electron microscope at a magnification of $\times 3000$ with an accelerating voltage of $12 \mathrm{kV}$.

\subsection{Statistical analysis}

The data are presented as means \pm standard deviation. All experimental data were the average of at least three independent tests. Differences between experimental groups were calculated using Tukey's multiple comparison test. A $p$-value less than 0.05 was considered statistically significant.

\section{Results and discussion}

\subsection{Structural characterization of the PPI and xylose- modified PPI powder}

3.1.1. Degree of glycosylation. Glycosylation is a carbonylamino reaction that occurs between the reducing carbonyl end of a sugar and amino acid of protein at a suitable temperature and humidity, which is also known as the Maillard reaction. Numerous previous studies have indicated a significant improvement of the functional properties of products coming from Maillard reaction between polysaccharides and proteins. ${ }^{\mathbf{4 , 1 7}}$ In order to determine the effect of glycosylation on structural properties of xylose-modified PPI powder, the degree of glycosylation (DG) with different xylose ratio was determined. As shown in Fig. 1, when xylose increases from $1 \%$ to $5 \%$, DG is around $6.0 \%$ and no significant changes $(p>0.05)$ are observed. A significant linear increase $(p<0.05)$ in DG from $6.0 \%$ to $10.7 \%$ is observed between 5 and $20 \%$ of xylose. It suggests that a threshold level of xylose is required for an effective glycosylation. From this threshold an increased level of xylose may enhance the crosslinking between PPI and xylose through Maillard reaction.

3.1.2. Surface hydrophobicity. Surface hydrophobicity $\left(H_{0}\right)$, an index of the number of hydrophobic groups on the surface of a protein molecule in contact with the polar aqueous environment, is closely related to its functional properties. ${ }^{15}$ Generally,

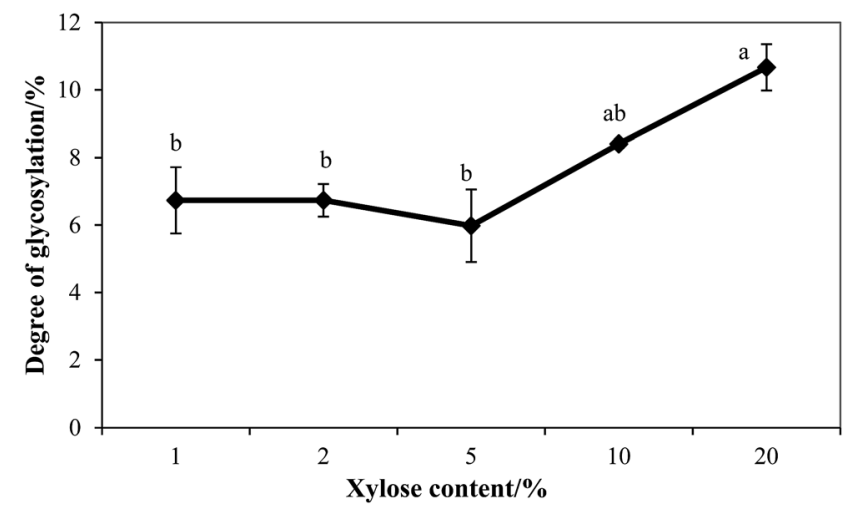

Fig. 1 Effect of xylose content on the degree of glycosylation of peanut protein isolate different letters ( $a$ and $b$ ) indicate significant differences $(p<0.05)$. protein films with higher surface hydrophobicity have a better potential to overcome the problem of film solubility and hygroscopy. ${ }^{18}$ The index of $H_{0}$ for PPI-X power was determined by the fluorescence emission spectra of ANS. As shown in Fig. 2, the surface hydrophobicity of PPI-X is significantly increased from 130.6 to 284.4 (2.2 times higher) with the addition of $1 \%$ xylose. The addition of $2 \%$ xylose increases surface hydrophobicity by about 2.5 times comparatively to $H_{0}$ for the sample without xylose, and the addition of 5\% xylose increases this value by 2.7 times. Almost similar trend in surface hydrophobicity was reported in soy protein film crosslinking with transglutaminase ${ }^{18}$ and glucomannan. ${ }^{9}$ The observed increase may be attributed to the partial unfolding of protein molecules during the xylose-modified PPI preparation..$^{18}$ Thus, the change of protein structure could lead to the exposition of the hydrophobic groups located within the hydrophobic core of proteins, and hence, increase the covalent bond number between xylose molecules and PPI.

3.1.3. FTIR detection of glycosylation reactions. IR spectroscopy would be valuable for detecting the presence of glycosyl groups on proteins. ${ }^{19}$ The main absorption peaks are located in the spectral range $3600-3000 \mathrm{~cm}^{-1}$ which are attributed to free and bound $\mathrm{O}-\mathrm{H}$ and $\mathrm{N}-\mathrm{H}$ groups. ${ }^{20,21}$ Other bands are observed in the $1700-1600 \mathrm{~cm}^{-1}$ amide $\mathrm{I}$ region governed by the stretching vibrations of $\mathrm{C}=\mathrm{O}$ and $\mathrm{C}-\mathrm{N}$ groups, ${ }^{22}$ in the amide II $1600-1500 \mathrm{~cm}^{-1}$ region associated to the $\mathrm{N}-\mathrm{H}$ bending, ${ }^{21,23}$ and in the range of $1000-1200 \mathrm{~cm}^{-1}$ corresponding to the stretching $\mathrm{C}-\mathrm{O}$ groups. ${ }^{21,24,25}$

The FTIR spectra of xylose and PPI glycosylated with different contents of xylose is shown in Fig. 3. It has been reported that the protein in the infrared region had several characteristics absorption band, including amide I (1600$\left.1700 \mathrm{~cm}^{-1}\right)$ and amide II (1600-1500 $\left.\mathrm{cm}^{-1}\right)$ which were the most valuable to study secondary structure..$^{22,26}$ All samples exhibit strong IR absorbance at around $1655 \mathrm{~cm}^{-1}, 1555 \mathrm{~cm}^{-1}$, corresponding to amide I and amide II bands respectively.

The spectra of the xylose and xylose-modified PPI have showed significant different in the 3600-3000 and 1200$1000 \mathrm{~cm}^{-1}$, as shown in Fig. 3a. In the $3600-3000 \mathrm{~cm}^{-1}$, free hydroxyl groups have stretching vibration absorption, and in

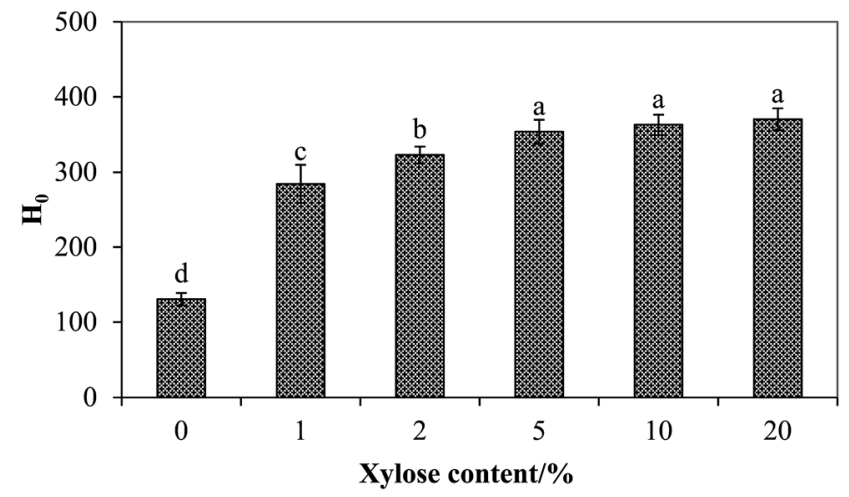

Fig. 2 Effect of xylose content on surface hydrophobicity of peanut protein isolate different letters $(a-d)$ indicate significant differences $(p<0.05)$. 

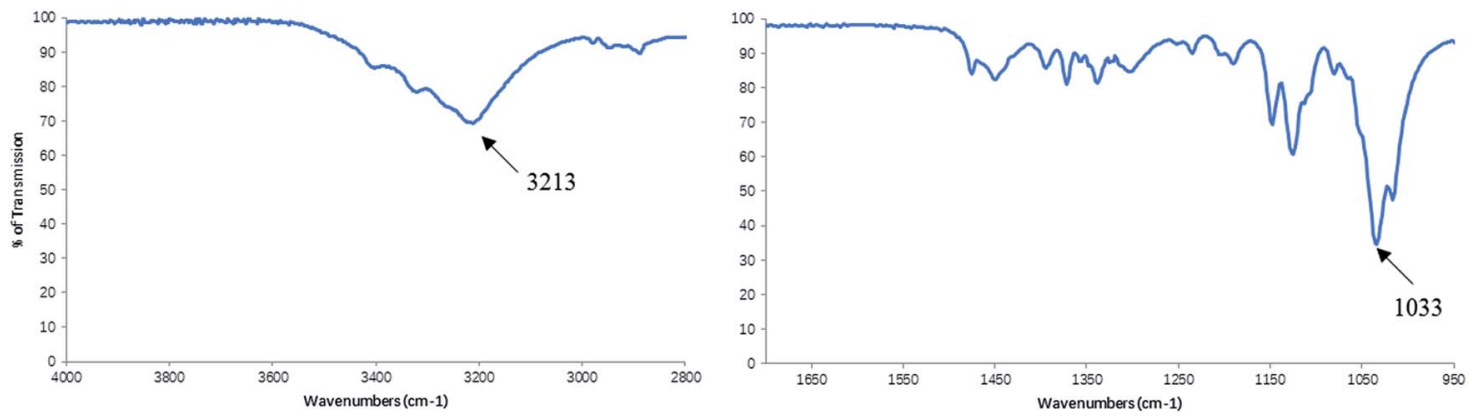

(a)

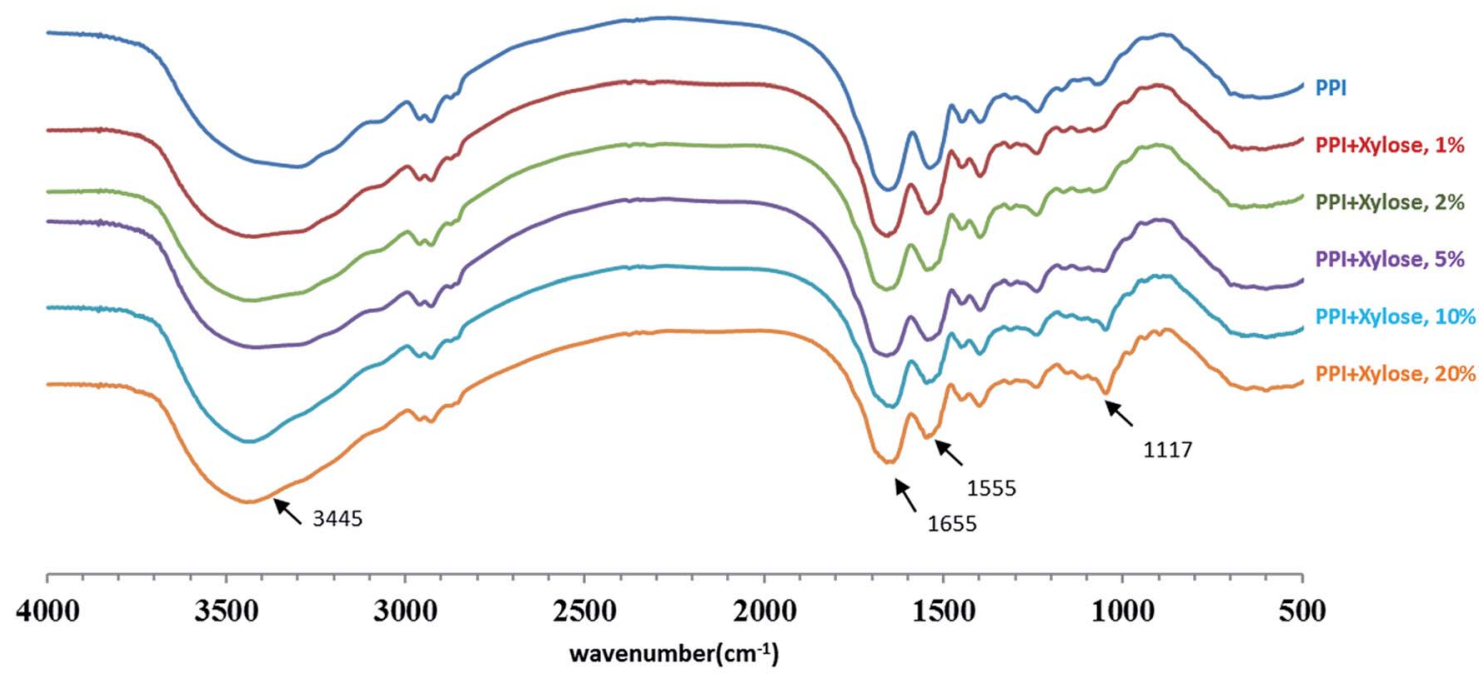

(b)

Fig. 3 FTIR absorbance spectra of xylose and xylose-modified PPI glycosylated with different xylose content. (a) xylose; (b) from top to bottom: PPI, $1 \%$ xylose, $2 \%$ xylose, $5 \%$ xylose, $10 \%$ xylose, $20 \%$ xylose.

the $1200-1000 \mathrm{~cm}^{-1}$ stretching vibrations of $\mathrm{C}-\mathrm{O}$ bond have strong absorption peak. When protein is conjugated with sugar molecules by covalent bond, the increasing hydroxyl content is a typical characteristic. This is expected because the sugars contain $\mathrm{OH}$ groups which contribute to an enhanced absorption of the free hydroxyl band..$^{19}$ In 3600-3000 and $1200-1000 \mathrm{~cm}^{-1}$, when analyzing the absorption peaks at $3445 \mathrm{~cm}^{-1}$ and $1117 \mathrm{~cm}^{-1}$ attributed to $-\mathrm{OH}$ and $\mathrm{C}-\mathrm{O}$ groups, we observed that the absorption of xylose-modified PPI is enhanced with xylose increasing, with a particular emphasis at $10 \%$ and $20 \%$ xylose.

Therefore, a broad absorption band at about $3445 \mathrm{~cm}^{-1}$ was observed for composites at xylose level 1-5\%, which can be attributed to the overlapping of free and bound $\mathrm{O}-\mathrm{H}$ xylose and $\mathrm{N}-\mathrm{H}$ groups coming from the protein. PPI-X composites showed a shift to high wavenumbers, and obviously lower width than PPI, with a particular emphasis at $10 \%$ and $20 \%$ xylose indicating the presence of $\mathrm{O}-\mathrm{H}$ groups. This could come from a higher degree of crosslinking between protein and xylose. ${ }^{27}$

\subsection{Mechanical, physical and structural properties of PPI-X films}

3.2.1. Mechanical properties. Mechanical properties of biopolymer films, mainly including tensile strength (TS) and elongation $(E)$, are extremely important from a technology point of view, since packaging materials must have adequate mechanical strength to maintain their integrity during handling and storage. ${ }^{12}$ To test the mechanical properties of the xylose-modified film, the xylose-modified PPI powder was dissolved in water to form films. PPI-X films showed significantly $(p<0.05)$ higher values of TS, $E$ than the control film PPI, as shown in Fig. 4. Moreover, when the xylose content was increased from 1 to $10 \%$, TS (5.3 MPa) and $E(103.0 \%)$ gradually increased. However, a further increase of xylose content from 10 to $20 \%$ decreases slightly the TS $(p<0.05)$ and $E$ values $(p>$ 0.05). Nevertheless, these values remained higher than the control film (Fig. 4). An improvement of TS has also been observed, for peanut protein film glycosylated with gum arabic, 


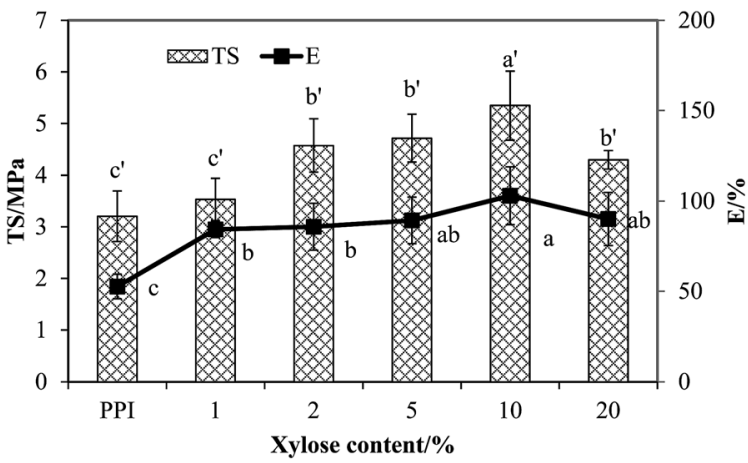

Fig. 4 Effects of glycosylation on mechanical properties of PPI-X film different letters $(a-c)$ and $\left(a^{\prime}-c^{\prime}\right)$ indicate significant differences between the film $(p<0.05)$.

and for soy protein film with glucomannan, respectively., ${ }^{9,11} \mathrm{~A}$ rising xylose content increases film tensile strength and elongation, due to the formation of covalent bond interaction between xylose and protein. ${ }^{9}$ However, such an increase only took place up to $10 \%$ xylose, above this value; the increase in xylose content did not produce any increase in tensile strength and elongation, probably due to film matrix saturation with xylose. For $20 \%$ xylose, plasticization could be probable with minor effect on stretching ability. This is rather interesting as it is generally considered that increases in TS of protein films are accompanied by decreases in $E .^{18}$ The differences of filmforming mechanism by different cross-linking methods may explain the differences of these observations. In the present case of xylose cross-linking, both covalent cross-linkage and non-covalent interactions between protein molecules induced by xylose addition seem to be involved in the film network formation.

\subsubsection{Physical properties}

3.2.2.1. Film solubility in water. Film solubility can be viewed as a measure of the water resistance and the integrity of a film, is usually required for potentially commercial films. A way to evaluate this resistance is to measure the water solubility which is an indicator of film's hydrophilicity. ${ }^{28}$ Addition of xylose significantly decreased PPI-X film solubility $(p<$ 0.05),while the moisture content of PPI-X films was not changed significantly (in the range of $10.4 \pm 0.9 \%$ to $10.86 \pm$ $0.4 \%$ ) as shown in Fig. 5. Compared to PPI film, a sharply decrease (from $96.6 \%$ to $52.6 \%$ ) of the solubility of PPI-X film was observed with addition of $1 \%$ xylose. When the content of xylose varied from $1 \%$ to $10 \%$, the solubility of the films continually decreased to $43.4 \%$. When the xylose content reached $20 \%$, the solubility decreased slightly although no significant difference $(p>0.05)$ was found. This decrease in solubility can be attributed to the interactions between protein side chains and exposure of the free sulfhydryl (SH) groups and hydrophobic side chains induced by cross-linking. This observation is in agreement with results presented above, which showed significantly higher values of $H_{0}$ and higher degree of graft in the case of films with higher xylose content.

The PPI film dissolves immediately (Fig. 6(1-a)) after immersion in water and is disintegrated into small pieces. Most

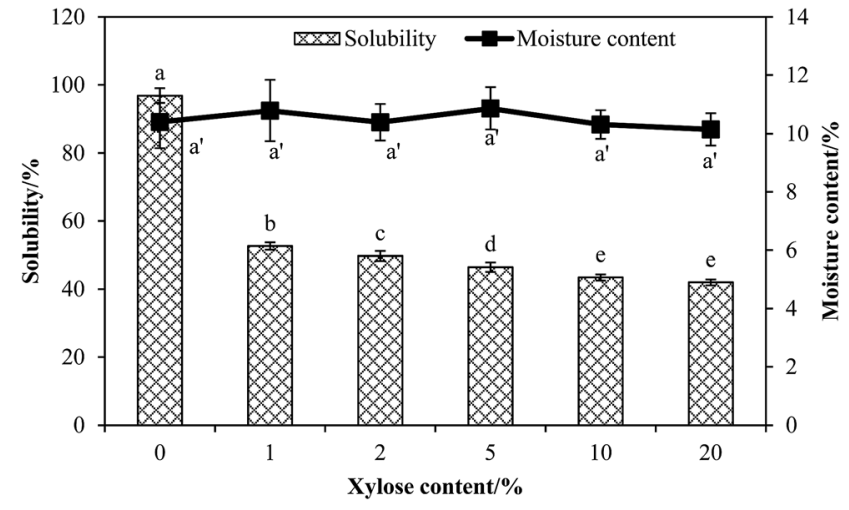

Fig. 5 Effect of xylose content on the solubility of PPI-X film different letters $(a-e)$ indicate significant differences of the film $(p<0.05)$.

of the films (xylose content $>2 \%$ ) maintain their integrity after incubation in water for $12 \mathrm{~h}$. However, only the $10 \%$ and $20 \%$ xylose containing films maintained their integrity after the film immersion for $24 \mathrm{~h}$. This indicated that the protein polymer network in presence of $10 \%$ or $20 \%$ of xylose was highly stable and that probably only small molecules such as small peptides, and non protein material were soluble..$^{29}$

3.2.2.2. Colour. The colour of a food product makes a great contribution to the consumers' willingness to buy it. ${ }^{28}$ Thus, to better evaluate the acceptability of PPI-X films, colour parameters $L^{*}, a^{*}, b^{*}$ were analyzed, as well as the total colour difference $(\Delta E)$ due to xylose addition was determined. The effect of xylose content on the color of PPI-X films is shown in Table 1. PPI-X films show high lightness ( $L^{*}$ parameter) values, which remains fairly constant, with a slightly decreasing tendency due to addition of xylose. However, an increasing content from $1 \%$ to $20 \%$ of xylose causes a slight decrease ( $p>$ $0.05)$ in the value of redness $a^{*}(2.4-2.7)$ and $b^{*}(11.8-12.7)$. The color change of the film is mainly caused by the products coming from Maillard reaction..$^{30}$ The tendency of increasing values of $a^{*}$ and $b^{*}$ was obtained for other protein films containing saccharides. ${ }^{9}$ Taking into account statistical data, the total colour difference $(\Delta E)$ is not significantly affected by the addition of xylose, showing that incorporation of xylose in PPI film does not significantly affect the appearance of the food product.

\subsubsection{Structural properties}

3.2.3.1 Sulfhydryl group content. As it can be seen from Fig. 7, the SH content of all PPI-X films is significantly lower than the one corresponding to xylose-modified PPI powder. The higher SH contents of xylose-modified PPI powder correlates with the lower SH contents of PPI-X films. When the xylose level increases from $1 \%$ to $10 \%$, a gradually decrease of SH contents of PPI-X films is observed, and reaches a minimum value of 1.8 $\mu \mathrm{mol} \mathrm{g}^{-1}$ at $10 \%$. Glycation-induced cross-linking through covalent bonding exposes the free sulfhydryl groups and favors the formation of new disulfide bonds due to the evaporation of solvent during drying step of film formation. ${ }^{31}$ However, when the xylose content is increased from $10 \%$ to $20 \%$, SH content of PPI-X film increases $(p<0.05)$. That can be explained by the fact 


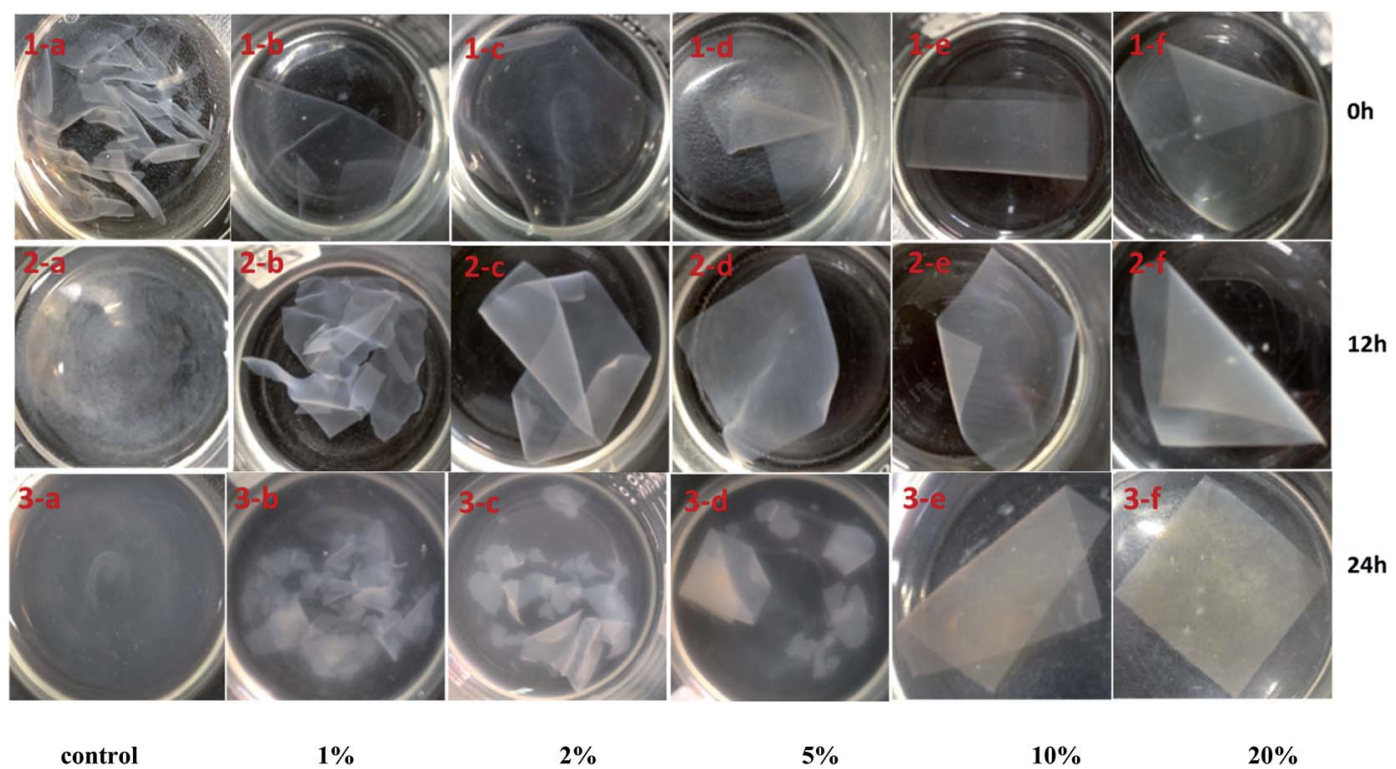

Fig. 6 Pictorial view of dissolution (solubility) of PPI and PPI-X film. The first, second and third row show solubility of PPI-X film when immersed in water for $0 \mathrm{~h}, 12 \mathrm{~h}$ and $24 \mathrm{~h}$, respectively.

Table 1 Effect of xylose content on the color of PPI-X films ${ }^{a}$

\begin{tabular}{|c|c|c|c|c|c|c|}
\hline \multirow[b]{2}{*}{ Value } & \multicolumn{6}{|c|}{ Xylose concentration (\%) } \\
\hline & 0 & 1 & 2 & 5 & 10 & 20 \\
\hline$a^{*}$ & $2.39 \pm 0.19^{\mathrm{a}}$ & $2.52 \pm 0.20^{\mathrm{a}}$ & $2.41 \pm 0.27^{\mathrm{a}}$ & $2.53 \pm 0.29^{\mathrm{a}}$ & $2.54 \pm 0.27^{\mathrm{a}}$ & $2.66 \pm 0.22^{\mathrm{a}}$ \\
\hline$b^{*}$ & $11.84 \pm 0.63^{\mathrm{a}}$ & $11.92 \pm 0.53^{\mathrm{a}}$ & $11.81 \pm 1.08^{\mathrm{a}}$ & $12.32 \pm 0.83^{\mathrm{a}}$ & $12.28 \pm 0.59^{\mathrm{a}}$ & $12.67 \pm 0.85^{\mathrm{a}}$ \\
\hline$\Delta E$ & $12.68 \pm 0.69^{\mathrm{a}}$ & $12.89 \pm 0.17^{\mathrm{a}}$ & $12.92 \pm 1.62^{\mathrm{a}}$ & $13.11 \pm 1.14^{\mathrm{a}}$ & $13.21 \pm 0.89^{\mathrm{a}}$ & $13.74 \pm 1.01^{\mathrm{a}}$ \\
\hline
\end{tabular}

${ }^{a}$ Mean values in the same row with same letters are not significantly $(p>0.05)$ different, as determined by Tukey's multiple range test.

that the number of hydroxyl groups of xylose increases, which enhances the absorption of water molecules, and thus constrains the interaction of sulfhydryl groups. It is in agreement with results presented below, which show less compact structures of PPI-X film upon $20 \%$ xylose.

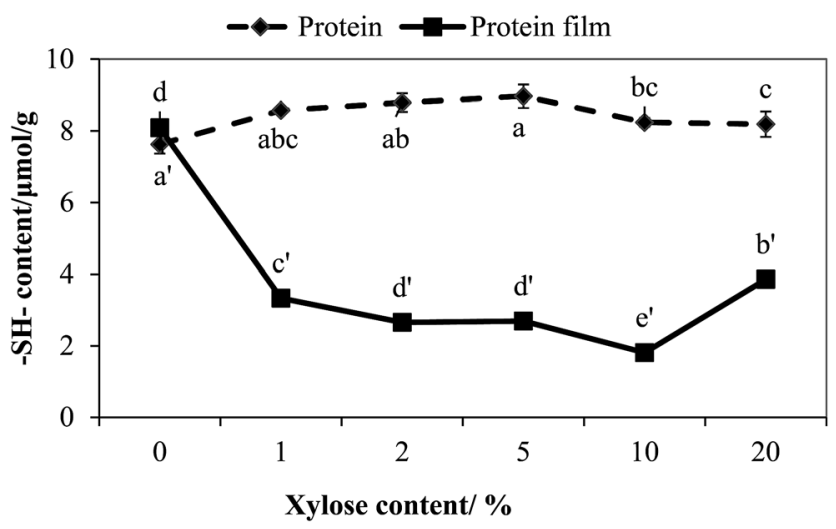

Fig. 7 Effect of xylose content on sulfhydryl group content of PPI-X and PPI-X films different letters $(a-d)$ and $\left(a^{\prime}-e^{\prime}\right)$ indicate significant differences between the film $(p<0.05)$.
3.2.3.2 Microstructure. The mechanical and physical properties of protein films are closely related to their microstructural characteristics, which are highly influenced by the film formulation and the manufacturing process. SEM was used to visualize the surface of each film. Imaging of the film structure is useful to understand the film behavior and properties. ${ }^{32}$ The micrographs of the PPI and PPI-X films are shown in Fig. 8. PPI film displays ridges, valleys, pores and cracks in the crosssection of films. With $1 \%$ xylose content, the PPI-X film shows a more smooth structure, but loose lamellar structure, with less pores or cracks. When xylose content increases from $2 \%$ to $5 \%$, less loose lamellar in PPI-X films is observed, but pores or cracks are observed. It can explain the gradual improvement of the tensile strength of PPI-X film with increase of xylose content (Fig. 4). When xylose content increased to $10 \%$, the PPI-xylose films become relatively more dense and compact with a reduced film heterogeneity, but little pores can still be observed. It suggests that the dense structure is caused by intermolecular covalent and non-covalent interactions, ${ }^{9,11,33}$ indicating the effectiveness of the glycosylation between PPI and xylose. Anker ${ }^{32}$ reported that water evaporates resulting in a denser structure with smaller pores. However, when xylose 


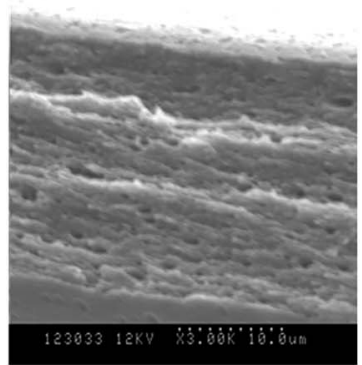

a. PPI

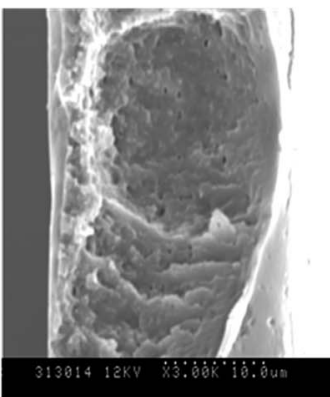

d. $5 \%$

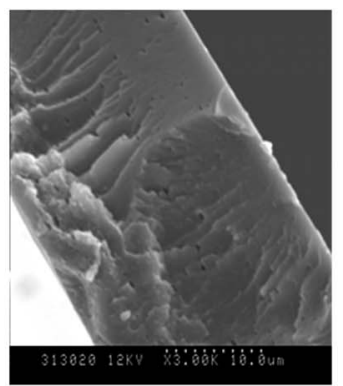

b. $1 \%$

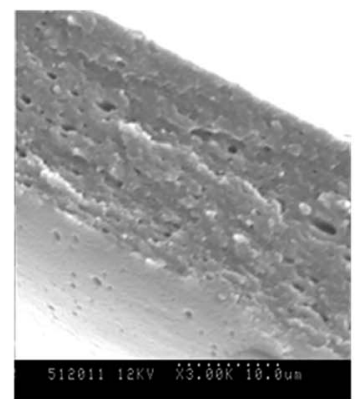

e. $10 \%$

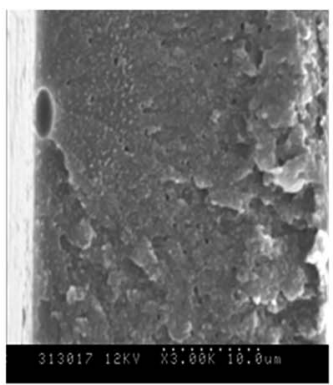

c. $2 \%$

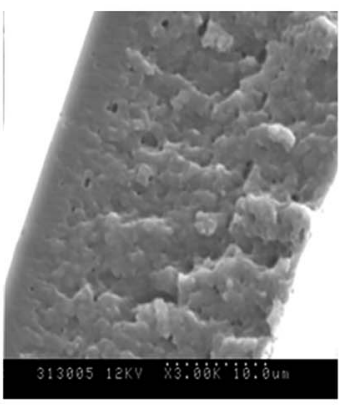

f. $20 \%$

Fig. 8 SEM micrographs of PPI and PPI-X films, (a) PPI film, (b) with $1 \%$ xylose, (c) with $2 \%$ xylose, (d) with $5 \%$ xylose, (e) with $10 \%$ xylose, (f) with $20 \%$ xylose $(\times 3000)$.

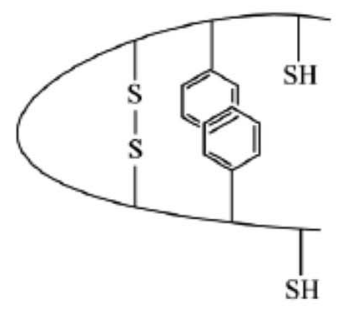

Peanut protein isolate before glycosylation

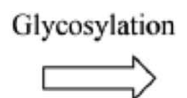

Xylose (X)

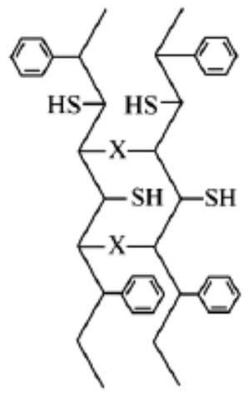

Peanut protein isolate after glycosylation

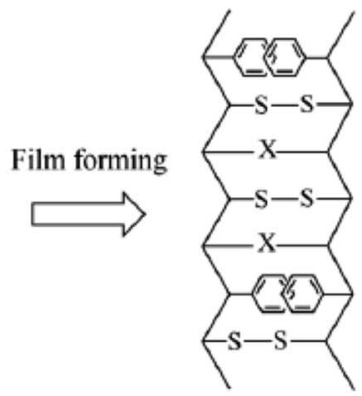

Peanut protein film glycosylated with xylose

Fig. 9 Mechanism of glycosylation of PPI for film properties improvement.

content reaches $20 \%$, a non-smooth structure with large clumps appears, which is probably due to the formation of more macromolecular polymers. ${ }^{9}$ Since increasing the concentration of reactants could increase the glycosylation yield, it could also result in greater protein denaturation and polymerization/ aggregation. ${ }^{34,35}$ So this structure may result in a film with weaker mechanical properties.

3.2.4 Mechanism of glycosylation of PPI for film properties improvement. To elucidate why glycosylation between the peanut isolated proteins and the xylose improves the mechanical and resistant properties of PPI-X film, a correlation analysis between protein structure and film properties was performed. DG, $H_{0}$, sulfhydryl group content of PPI-X have a significant positive correlation with tensile strength and elongation, and expectably have negative correlation with TSM. However, the sulfhydryl group content of PPI-X film has opposite trends (data not shown). As suggested in Fig. 9, after glycosylation with xylose, protein molecules unfold greatly, exposing the internal hydrophobic and sulfhydryl groups. Then hydrophobic interaction and disulfide bonds were formed in the protein network, which can bear high degree of deformation, resulting in improvement of tensile strength and elongation of the films. Moreover, the exposure of hydrophobic groups weakens the hydrophilicity of protein and enhances the hydrophobicity; improving therefore the water resistance of the protein film.

\section{Conclusion}

The effect of xylose content on the structural and functional properties of PPI-X films was investigated. PPI-X films has 
some superior characteristics, e.g., much higher tensile strength and elongation, lower total soluble mass, as compared to PPI films. The results indicate that the addition of xylose improves the structural and mechanical properties of the film. Compared to PPI, DG and $H_{0}$ of xylose-modified PPI increase with increasing xylose content. Different contents of xylose have significant effect on the physical and structural properties of the PPI-xylose films. Presence of xylose until a level of $10 \%$ increases the tensile strength and the elongation and decreases the solubility of PPI-X films. Overall results from this study indicate that the film properties improvement obtained by blending xylose with PPI can be attributed to covalent (Maillard reaction) and non-covalent interaction occurring between xylose and PPI. Moreover, glycosylated PPI-X solution could be converted into powder. Glycosylated PPI powder can then be used as material for film production, which enhances the convenience of transportation and storage, and provides more alternatives for peanut protein film production including solution casting, compression moulding and blow moulding. It is also more convenient to scale up to an industrial production. So the films developed in this work are suggested to be suitable for food inside packing, e.g. flavoring bag.

\section{Conflicts of interest}

There are no conflicts to declare.

\section{Acknowledgements}

This study was financially supported by National Key R\&D Program of China (2016YFD0400205), and the Agricultural Science and Technology Innovation Program. The authors also acknowledge the laboratory facility and technical assistance of the Key Laboratory of Agro-Products Processing, Ministry of Agriculture of China. We thank the University of LiègeGembloux Agro-Bio Tech and more specifically the research platform AgricultureIsLife for the funding of the scientific stay in Belgium that made this paper possible. M. D. thanks the Fund for National Scientific Research in Belgium (FNRS) for her position has Senior Research Associate. MNN is working for the ARC-FIELD project 3/17-10.

\section{References}

1 H. Tian, G. Xu, B. Yang and G. Guo, Microstructure and mechanical properties of soy protein/agar blend films: Effect of composition and processing methods, J. Food Eng., 2011, 107(1), 21-26.

2 R. Kuktaite, T. S. Plivelic, Y. Cerenius, M. S. Hedenqvist, M. Gallstedt, S. Marttila, R. Ignell, Y. Popineau, O. Tranquet, P. R. Shewry, et al., Structure and morphology of wheat gluten films: From polymeric protein aggregates toward superstructure arrangements, Biomacromolecules, 2011, 12(5), 1438-1448.

3 N. Reddy, L. Chen and Y. Yang, Thermoplastic films from peanut proteins extracted from peanut meal, Ind. Crops Prod., 2013, 43(1), 159-164.
4 W. J. Lin, H. Z. Liu, A. M. Shi, L. Liu, B. Adhikari and Q. Wang, Preparation and characterisation of films from xylose-glycosylated peanut protein isolate powder, Int. J. Food Sci. Technol., 2015, 50(7), 1538-1544.

5 N. Reddy, Q. Jiang and Y. Yang, Preparation and properties of peanut protein films crosslinked with citric acid, Ind. Crops Prod., 2012, 39(1), 26-30.

6 F. Hammann and M. Schmid, Determination and quantification of molecular interactions in protein films: A review, Materials, 2014, 7(12), 7975-7996.

7 W. J. Lin, H. Z. Liu, A. M. Shi, L. Liu, Q. Wang and B. Adhikari, Effect of glycosylation with xylose on the mechanical properties and water solubility of peanut protein films, J. Food Sci. Technol., 2015, 52(10), 6242-6253.

8 G. Rocha Plácido Moore, S. Maria Martelli, C. Gandolfo, P. José do Amaral Sobral and J. Borges Laurindo, Influence of the glycerol concentration on some physical properties of feather keratin films, Food Hydrocolloids, 2006, 20(7), 975-982.

9 H. Zhang, S. Wang, X. Zheng, L. Jiang, X. Lv, Y. Shi and L. Li, Effect of glycosylation on the mechanical properties of edible soy protein packaging film, Eur. Food Res. Technol., 2014, 238(6), 1049-1055.

10 L. M. Pérez, G. N. Piccirilli, N. J. Delorenzi and R. A. Verdini, Effect of different combinations of glycerol and/or trehalose on physical and structural properties of whey protein concentrate-based edible films, Food Hydrocolloids, 2016, 56, 352-359.

11 C. Li, W. Zhu, H. Xue, Z. Chen, Y. Chen and X. Wang, Physical and structural properties of peanut protein isolate-gum Arabic films prepared by various glycation time, Food Hydrocolloids, 2015, 43, 322-328.

12 M. Wihodo and C. I. Moraru, Physical and chemical methods used to enhance the structure and mechanical properties of protein films: A review, J. Food Eng., 2013, 114(3), 292-302.

13 R. Sothornvit and J. M. Krochta, Plasticizer effect on mechanical properties of $\beta$-lactoglobulin films, J. Food Eng., 2001, 50(3), 149-155.

$14 \mathrm{H}$. Zhang and Y. Chi, Modified soy protein isolate with improved gelling stability by glycosylation under the conditions of ocean shipping, Int. J. Food Sci. Technol., 2011, 46(1), 14-22.

15 X.-H. He, H.-Z. Liu, L. Liu, G.-L. Zhao, Q. Wang and Q.-L. Chen, Effects of high pressure on the physicochemical and functional properties of peanut protein isolates, Food Hydrocolloids, 2014, 36, 123-129.

16 T. Beveridge, S. J. Toma and S. Nakai, Determination of Shand Ss-Groups in Some Food Proteins Using Ellman'S Reagent, J. Food Sci., 1974, 39(1), 49-51.

17 C. Li, H. Xue, Z. Chen, Q. Ding and X. Wang, Comparative studies on the physicochemical properties of peanut protein isolate-polysaccharide conjugates prepared by ultrasonic treatment or classical heating, Food Res. Int., 2014, 57, 1-7.

18 C. H. Tang and Y. Jiang, Modulation of mechanical and surface hydrophobic properties of food protein films by transglutaminase treatment, Food Res. Int., 2007, 40(4), 504-509. 
19 M. Khajehpour, J. L. Dashnau and J. M. Vanderkooi, Infrared spectroscopy used to evaluate glycosylation of proteins, Anal. Biochem., 2006, 348(1), 40-48.

20 J. F. Su, X. Y. Yuan, Z. Huang, X. Y. Wang, X. Z. Lu, L. D. Zhang and S. B. Wang, Physicochemical properties of soy protein isolate/carboxymethyl cellulose blend films crosslinked by Maillard reactions: Color, transparency and heat-sealing ability, Mater. Sci. Eng., C, 2012, 32(1), 40-46.

21 Ó. L. Ramos, I. Reinas, S. I. Silva, J. C. Fernandes, M. A. Cerqueira, R. N. Pereira, A. A. Vicente, M. F. Poças, M. E. Pintado and F. X. Malcata, Effect of whey protein purity and glycerol content upon physical properties of edible films manufactured therefrom, Food Hydrocolloids, 2013, 30(1), 110-122.

22 H. Yang, S. Yang, J. Kong, A. Dong and S. Yu, Obtaining information about protein secondary structures in aqueous solution using Fourier transform IR spectroscopy, Nat. Protoc., 2015, 10(3), 382-396.

23 E. Vass, M. Hollósi, F. Besson and R. Buchet, Vibrational spectroscopic detection of beta- and gamma-turns in synthetic and natural peptides and proteins, Chem. Rev., 2003, 103(5), 1917-1954.

24 P. Guerrero and K. De La Caba, Thermal and mechanical properties of soy protein films processed at different $\mathrm{pH}$ by compression, J. Food Eng., 2010, 100(2), 261-269.

25 X. Geng, B. Cui, Y. Li, W. Jin, Y. An, B. Zhou, T. Ye, L. He, H. Liang, L. Wang, et al., Preparation and characterization of ovalbumin and carboxymethyl cellulose conjugates via glycosylation, Food Hydrocolloids, 2014, 37, 86-92.

26 M. Deleu, J. M. Crowet, M. N. Nasir and L. Lins, Complementary biophysical tools to investigate lipid specificity in the interaction between bioactive molecules and the plasma membrane: A review, Biochim. Biophys. Acta, Biomembr., 2014, 1838(12), 3171-3190.
27 Y. Jiang, Y. Li, Z. Chai and X. Leng, Study of the physical properties of whey protein isolate and gelatin composite films, J. Agric. Food Chem., 2010, 58(8), 5100-5108.

$28 \mathrm{~S}$. Galus and J. Kadzińska, Whey protein edible films modified with almond and walnut oils, Food Hydrocolloids, 2016, 52, 78-86.

29 L. A. Kunte, M. A. Hanna and C. L. Weller, Cast Films from Soy Protein Isolates and Fractions, Cereal Chem., 1997, 74(2), 115-1118.

30 G. L. A. Makishi, R. S. Lacerda, A. M. Q. B. Bittante, H. N. M. Chambi, P. A. Costa, C. A. Gomide, R. A. Carvalho and P. J. A. Sobral, Films based on castor bean (Ricinus communis L.) proteins crosslinked with glutaraldehyde and glyoxal, Ind. Crops Prod., 2013, 50, 375-382.

31 L. Chin-Chi, A. M. Tellez-Garay and M. E. Castell-Perez, Physical and mechanical properties of peanut protein films, Lebensm.-Wiss. Technol., 2004, 37(7), 731-738.

32 M. Anker, M. Stading and A.-M. Hermansson, Relationship between the Microstructure and the Mechanical and Barrier Properties of Whey Protein Films, J. Agric. Food Chem., 2000, 48(9), 3806-3816.

33 K. Chang, J. R. Williamson and H. S. Zarkowsky, Effect of heat on the circular dichroism of spectrin in hereditary pyropoikilocytosis, J. Clin. Invest., 1979, 64(1), 326-328.

34 F. C. D. Oliveira, J. S. D. R. Coimbra, E. B. de Oliveira, A. D. G. Zuñiga and E. E. G. Rojas, Food ProteinPolysaccharide Conjugates obtained via the Maillard Reaction: A Review, Crit. Rev. Food Sci. Nutr., 2016, 56(7), 1108-1125.

35 D. Zhu, S. Damodaran and J. A. Lucey, Formation of whey protein isolate (WPI)-dextran conjugates in aqueous solutions, J. Agric. Food Chem., 2008, 56(16), 7113-7118.

36 Q. Wang, Peanuts: Processing Technology and Product Development, Academic Press, 1st edn, 2016. 